\title{
Perfil químico, atividade antimicrobiana do extrato das sementes de urucum (bixa orellana)
}

\author{
Chemical Profile, Antimicrobial Activity of seeds extract of Urucum (Bixa \\ orellana)
}

\author{
Isadora Oliveira de Carvalho ${ }^{1}$, Francisco Antônio Félix Xavier Júnior ${ }^{1 *}$, Janaina Serra Azul \\ Monteiro Evangelista ${ }^{1}$, Fabíola Fernandes Galvão Rodrigues ${ }^{2}$, José Galberto Martins da Costa ${ }^{2}$
}

\section{RESUMO}

Bixa orellana é uma planta advinda da América do Sul, comumente utilizada para fins econômicos e terapêuticos. Este estudo teve como objetivo determinar o perfil químico e avaliar a atividade antimicrobiana do extrato acetônico das sementes de Bixa orellana. A identificação e quantificação dos compostos químicos foi realizada através de prospecção fitoquímica e por CLAE-DAD (Cromatografia Líquida de Alta Eficiência - detector de arranjo de diodos). A análise da atividade antimicrobiana foi realizada através do método de microdiluição em caldo e determinada a Concentração Inibitória Mínima (CIM) para cepas padrão bacterianas e fúngicas. Foi identificada a presença de fenóis e flavonoides. O extrato apresentou atividade antibacteriana significativa (CIM<1000 $\mu \mathrm{g} / \mathrm{ml}$ ) contra cepas padrão Escherichia coli, Proteus vulgaris, Pseudomonas aeruginosa, Vibrio cholareae e Staphylococcus aureus. Entretato não houve inibição do crescimento fúngico para Aspergillus niger e Penicillium notatum. Com os resultados obtidos, é possível inferir que o extrato de B. orellana apresenta compostos bioativos com propriedades antibacterianas.

Palavras-chave: Composição química; Extrato acetônico; Flavonoides; Fenóis; Resistência bacteriana.

\section{ABSTRACT}

Bixa orellana is a plant from South of America, commonly used for economic and therapeutic purposes. This study aimed to determine the chemical profile and evaluate the antimicrobial activity of the acetone Bixa orellana seeds extract. The identification and quantification of chemical compounds was performed by phytochemical prospection and by HPLC-DAD (High Performance Liquid Chromatography - Diode Arrangement Detector). The analysis of antimicrobial activity was performed using the broth microdilution assay and the Minimum Inhibitory Concentration (MIC) was determined for standard bacterial and fungal strains. The presence of phenols and flavonoids was identified. The extract showed significant antibacterial activity (MIC $<1000 \mu \mathrm{g} / \mathrm{ml}$ ) against standard strains Escherichia coli, Proteus vulgaris, Pseudomonas aeruginosa, Vibrio cholareae and Staphylococcus aureus. However, there was no inhibition of fungal growth for Aspergillus niger and Penicillium notatum. With the results obtained, it is possible to infer that the extract of B. orellana has bioactive compounds with antibacterial properties.

Keywords: Chemical composition; Acetone extract; Flavonoids; Phenols; Bacterial resistance.

\footnotetext{
${ }^{1}$ Universidade Estadual do Ceará

*E-mail: juniorfelix.medicoveterinario@gmail.com

${ }^{2}$ Universidade Regional do Cariri
} 


\section{INTRODUÇÃO}

As plantas têm sido amplamente utilizadas como fonte de inúmeras substâncias, ao longo de gerações, como fragrâncias, aromatizantes, inseticidas, pigmentos e no tratamento de diversas enfermidades (Fachini et al., 2012), contribuindo para a descoberta e desenvolvimento de novas ferramentas farmacológicas (Newman; Cragg, 2020).

Bixa orellana é uma planta arbustiva pertencente à família Bixaceae originária da América do Sul (Silva et al., 2010). Sua importância econômica se dá principalmente devido às suas sementes, que produzem um corante natural, amplamente utilizado na indústria alimentícia em substituição aos corantes sintéticos (Leal; Clavijo, 2010; Guesmi et al., 2013).

Popularmente, B. orellana é utilizada como antipirético, afrodisíaco, antidiarreico, antidiabético e repelente de insetos. Estudos farmacológicos mostram que as sementes de B. orellana têm efeitos antimicrobianos, anti-inflamatórios, antioxidantes, hipoglicêmicos e citotóxicos (Shahidul-Islam et al., 2016; Vilar et al., 2014). As propriedades terapêuticas e aplicações industriais das sementes de urucum estão diretamente relacionadas ao conteúdo de carotenóides, especialmente a bixina, o principal apocarotenóide desta espécie (Priya et al., 2017; Rivera-Madrid et al., 2016).

Portanto, o objetivo deste estudo foi caracterizar o perfil fitoquímico e avaliar as atividades antibacterianas e antifúngicas e do extrato acetônico de B. orellana.

\section{MATERIAL E MÉTODOS}

\section{Coleta do Material Botânico}

As sementes de urucum foram obtidas no "Shopping Popular Belizário de Sousa Primo" localizado no centro do município de Crato, Ceará, Brasil.

\section{Preparação do Extrato}

Para a preparação do extrato acetônico, 95 gramas das sementes da $B$. orellana foram macerados e submetidas à extração com acetona, em aparelhagem de Soxhlet por um período de 3 horas. Posteriormente, o material foi filtrado e transferido para um evaporador rotativo acoplado em banho-maria, para a completa remoção de qualquer traço de solvente orgânico.

\section{Prospecção Fitoquímica}


A identificação das classes de compostos químicos foi realizada de acordo com a metodologia de Matos (1997). Os testes foram baseados na observação visual da mudança colorimétrica e/ou formação de precipitados após a adição de reagentes específicos na solução do extrato.

\section{Quantificação de compostos por Cromatografia Líquida de Alta Eficiência (CLAE)}

A análise cromatográfica foi realizada em sistema CLAE-DAD (Shimadzu, Kyoto, Japão), destaque Auto Sampler (SIL-20A), equipado com Shimadzu LC-20AT com duas bombas alternadas ligadas ao desgaseificador DGU 20A5 com o integrador CBM 20, UV-VIS com detector DAD (detector de arranjo de diodos) SPD-M20A e Software LC solução 1,22 SP1. Foram utilizadas colunas C18 (4,6 mm x $250 \mathrm{~mm}) \mathrm{com}$ partículas medindo $5 \mu \mathrm{m}$ de diâmetro. As amostras foram dissolvidas em solvente polar em concentrações pré-determinadas. Foram utilizados padrões de compostos fenólicos (ácidos gálico, clorogênico e caféico) e flavonoides (quercetina, rutina e campferol) para comparação de perfis e tempos de retenção. A análise cromatográfica foi realizada em temperatura ambiente e em triplicata. O limite de detecção (LOD) e o limite de quantificação (LOQ) foram calculados com base no desvio padrão das respostas e no declive das três curvas analíticas independentes utilizadas (Boligon et al., 2015).

\section{Determinação da concentração inibitória mínima (CIM)}

Os microorganismos utilizados foram obtidos através do Instituto Nacional de Controle de Qualidade em Saúde (INCQS) da Fundação Oswaldo Cruz - Fiocruz, Ministério da Saúde. Cinco linhagens padrão de bactérias foram utilizadas, sendo quatro gram-negativas Escherichia coli (ATCC 25922), Proteus vulgaris (ATCC 13315), Pseudomonas aeruginosa (ATCC15442), Vibrio cholareae (ATCC 15748) e uma grampositiva Staphylococcus aureus (ATCC 6538), além de duas linhagens de fungos Aspergillus niger (ATCC 16404) e Penicillium notatum (ATCC 40012).

Os ensaios para determinação da CIM do extrato foram efetuados através do método de microdiluição em caldo (NCCLS, 2003), em placas de microdiluição de 96 poços, com concentrações variando de 1024 a $0,5 \mu \mathrm{g} / \mathrm{mL}$. As suspensões bacterianas previamente padronizadas foram suspensas em caldo BHI para a obtenção da concentração final de $10^{5} \mathrm{UFC} / \mathrm{mL}$. As placas de microdiluição foram incubadas por 24 horas a $37^{\circ} \mathrm{C}$. Após a incubação, a solução rezarurina sódica foi adicionada em cada poço 
da placa como indicador colorimétrico de crescimento bacteriano, com a mudança de coloração azul para rosa (Palomino et al., 2002). A CIM foi determinada como sendo a menor concentração do extrato responsável por inibição do crescimento bacteriano.

Quanto às suspensões fúngicas, estas foram previamente preparadas em meio PDA (Ágar batata dextrose) e levadas para a estufa por um período de 96h. Após esse período, foram realizadas microdiluições em placa juntamente com o extrato de urucum e levadas para a estufa por um período de $24 \mathrm{~h}$ a $37^{\circ} \mathrm{C}$. A presença de turvação foi o indicativo de crescimento fúngico.

\section{Análise Estatística}

Os resultados dos ensaios para os testes de CLAE foram analisados pelo modelo ANOVA e teste de Tukey e expressos como média \pm D.P. Resultados com $p<0,05$ foram considerados estatisticamente significativos.

\section{RESULTADOS}

Prospecção fitoquímica

No teste de prospecção fitoquímica, o extrato de B. orellana indicou a presença das seguintes classes de metabólitos: fenóis e flavonóides (flavonas, flavononas, flavonóis, flavononóis, xantonas, chalconas, auronas) (Tabela 1).

Tabela 1 - Perfil fitoquimico do extrato acetônico das sementes de B. orellana; 1: Fenóis; 2: Flavononas; 3: Flavonois; 4: Flavononóis; 5: Flavonas; 6: Xantonas; 7: Chalconas; 8: Auronas; 9: Alcaloides; (+) presença; (-) ausência.

\section{Classes de metabólitos}

\begin{tabular}{llllllllll} 
& 1 & 2 & 3 & 4 & 5 & 6 & 7 & 8 & 9 \\
\hline Extrato & + & + & + & - & + & + & + & + & - \\
\hline
\end{tabular}

Fonte: Próprio autor

Análise do perfil da CLAE-DAD.

Através das análises por CLAE, o extrato acetônico de $B$. orellana revelou a presença de ácido gálico (tempo de retenção-tR = 12,07 min; pico 1), catequina ( $\mathrm{tR}=$ 15,92 min; pico 2), ácido clorogênico ( $\mathrm{tR}=20,35 \mathrm{~min}$; pico 3), ácido cafeico ( $\mathrm{tR}=22,18$ min; pico 4), derivado ácido cafeico ( $\mathrm{tR}=24,67 \mathrm{~min}$; pico 5), ácido elágico ( $\mathrm{tR}=29,04$ 
min; pico de 6), epicatequina ( $\mathrm{tR}=31,85 \mathrm{~min}$; pico de 7), luteolina ( $\mathrm{tR}=38,01 \mathrm{~min}$; pico de 8), derivado luteolina ( $\mathrm{tR}=39,97 \mathrm{~min}$; pico de 9), apigenina ( $\mathrm{tR}=44,19 \mathrm{~min}$; pico 10) e quercetina ( $\mathrm{tR}=48,03 \mathrm{~min}$; pico 11) (Figura 1 e Tabela 2), evidenciando a presença de diferentes tipos e concentrações de ácidos fenólicos e flavonoides. A quercetina, apigenina e o derivado de luteolina foram os metabólitos com maiores tempos de retenção.

Dentre os compostos, o ácido cafeico, um ácido fenólico, apresentou maiores quantidades em relação aos outros componentes $(18,47 \pm 0,01 \mathrm{mg} / \mathrm{g})$, seguido pelos flavonoides luteolina $(14,18 \pm 0,02 \mathrm{mg} / \mathrm{g})$ e apigenina $(14,35 \pm 0,02 \mathrm{mg} / \mathrm{g})$. Em contrapartida, o flavonoide catequina, foi o composto que apresentou menor quantidade $(1,09 \pm 0,02 \mathrm{mg} / \mathrm{g})$.

Figura 1 - Representação do perfil da cromatografia líquida de alta eficiência do extrato acetônico das sementes de B. orellana. Ácido gálico (pico 1), catequina (pico 2), ácido clorogênico (pico 3), ácido caféico (pico 4), derivado ácido caféico (pico 5), ácido elágico (pico 6), epicatequina (pico 7), luteolina (pico 8), derivado luteolina (pico 9), apigenina (pico 10) e quercetina (pico 11).

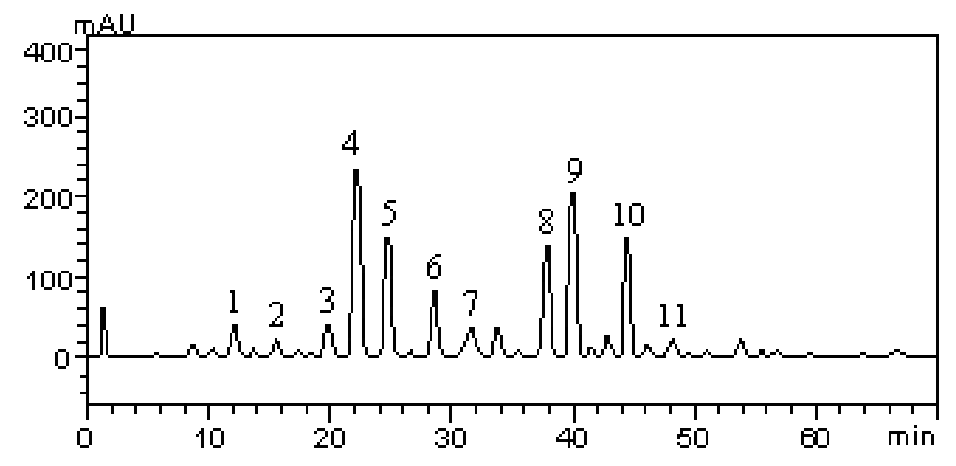

Fonte: Próprio autor

Tabela 2 - Composição de compostos fenólicos e flavonoides quantificados por CLAE em amostra de extrato acetônico de B. orellana. "Quantificado foi ácido cafeico, \# quantificado foi luteolina. LOD limite de detecção $(\mu \mathrm{g} / \mathrm{ml})$, LOQ limite de quantificação $(\mu \mathrm{g} / \mathrm{ml})$. Resultados são expressos em média \pm DP, para triplicatas. Médias seguidas por letras diferentes diferem pelo teste de Tukey $\mathrm{p}<0,05$.

\begin{tabular}{|c|c|c|c|c|}
\hline \multirow{2}{*}{ Composto } & \multicolumn{2}{|c|}{ Extrato acetônico } & \multirow{2}{*}{$\begin{array}{l}L O D \\
\mu \mathrm{g} / \mathrm{mL}\end{array}$} & \multirow{2}{*}{$\begin{array}{l}L O Q \\
\mu \mathrm{g} / \mathrm{mL}\end{array}$} \\
\hline & $\mathrm{mg} / \mathrm{g}$ & $\%$ & & \\
\hline Ácido gálico & $2,15 \pm 0,03^{\mathrm{a}}$ & 0,21 & 0,017 & 0,056 \\
\hline Catequina & $1,09 \pm 0,02^{\mathrm{b}}$ & 0,10 & 0,023 & 0,075 \\
\hline
\end{tabular}




$\begin{array}{lcccc}\text { Ácido clorogênico } & 2.31 \pm 0,01^{\mathrm{a}} & 0,23 & 0,009 & 0,030 \\ \text { Ácido caféico } & 18,47 \pm 0,01^{\mathrm{c}} & 1,84 & 0,035 & 0,114 \\ \text { Ácido caféico }^{\text {Aderivado) }}{ }^{*} & 13,92 \pm 0,02^{\mathrm{d}} & 1,39 & - & - \\ \text { Ácido elágico } & 7,05 \pm 0,01^{\mathrm{e}} & 0,70 & 0,012 & 0,039 \\ \text { Epicatequina } & 2,79 \pm 0,03^{\mathrm{a}} & 0,27 & 0,018 & 0,059 \\ \text { Luteolina } & 14,18 \pm 0,02^{\mathrm{d}} & 1,41 & 0,029 & 0,096 \\ \text { Luteolina (derivado) } & 17,39 \pm 0,01^{\mathrm{c}} & 1,73 & - & - \\ \text { Apigenina } & 14,35 \pm 0,02^{\mathrm{d}} & 1,43 & 0,031 & 0,102 \\ \text { Quercetina } & 1,56 \pm 0,02^{\mathrm{b}} & 0,15 & 0,040 & 0,132\end{array}$

Fonte: Próprio autor

\section{Atividade antimicrobiana}

No teste de microdiluição foi determinada a concentração inibitória mínima (CIM) do extrato de B. orellana contra as cepas testadas. Observou-se que o extrato apresentou valores de CIM inferiores a $1024 \mu \mathrm{g} / \mathrm{mL}$, variando entre 512 e $256 \mu \mathrm{g} / \mathrm{mL}$ (Tabela 3), mostrando que o extrato apresentou efeito antibacteriano. Em relação as análises frente às duas linhagens de fungos analisadas, A. niger e P. notatum, o extrato não obteve uma atividade antifúngica considerada satisfatória, com CIM $\geq 1024 \mu \mathrm{g} / \mathrm{mL}$.

Tabela 3 - Valor da CIM do extrato acetônico de B. orellana contra cepas bacterianas multirresistenes.

$$
\operatorname{MIC}(\mu \mathrm{g} / \mathrm{mL})
$$

\begin{tabular}{cc}
\hline Microrganismo testado & Extrato de B. orellana \\
\hline Escherichia coli ATCC 25922 & 512 \\
\hline Proteus vulgaris ATCC 13315 & 256 \\
\hline Pseudomonas aeruginosa ATCC15442 & 512 \\
\hline Vibrio cholerae ATCC 15748 & 256 \\
\hline Staphylococcus aureus ATCC 6538 & 512 \\
\hline
\end{tabular}

Fonte: Próprio autor

\section{DISCUSSÃO}

Os constituintes presentes nas plantas medicinais são importantes biomoléculas ativas, entre elas, os compostos fenólicos. Estes, podem ser classificados em fenóis 
(estruturas mais simples) como por exemplo o ácido caféico e o ácido gálico e em polifenóis (moléculas mais complexas), como é o caso dos flavonoides e estilbenos. Esses metabólitos apresentam diversas atividades incluindo, antioxidantes, antibacterianas, antifúngicas, anti-inflamatórias e antitumorais (Cheynier, 2012; Rodrigues et al., 2019).

Através da prospecção fitoquímica e CLAE-DAD, as sementes de B. orellana demonstraram a presença tanto de fenóis quanto de diversos flavonoides como visto também por Karmakar et al. (2018) e a ausência de alcaloides, assim como Fleisher et al. (2003) e dos componentes encontrados no extrato, o ácido caféico, a luteolina e apigenina foram os compostos encontrados em maiores quantidades.

Os fenóis são compostos aromáticos presente de forma abundante no reino vegetal (Mishra et al., 2009). Da classe dos fenóis e ácidos fenólicos, os ácidos cinâmico e caféico são os ativos mais comumente encontrados do grupo derivado do fenilpropano (Cowan, 1999), além disso, o ácido caféico é um dos principais compostos de maior interesse, por apresentar atividade antioxidante (Heleno et al., 2015).

A atividade dos flavonoides depende intrinsicamente de sua estrutura química, grau de hidroxilação, substituições e conjugações, além do grau de polimerização (Kelly; Anthony; Dennis, 2002).

O extrato de B. orellana foi efetivo em inibir o crescimento tanto de bactérias gram negativas quanto da gram positiva, tendo um efeito maior nas gram negativas $P$. vulgaris e $V$. cholerae. Tanto os fenóis quanto os flavonoides presentes no extrato das sementes de $B$. orellana, podem ter sido os responsáveis pela inibição do crescimento bacteriano. Fleisher et al. (2003) e Karmakar et al. (2018) também observaram uma inibição do crescimento bacteriano com o extrato etanólico das sementes de B. orellana frente às bactérias S. aureus, P. aeruginosa e E. coli, assim como apresentado no presente estudo.

Segundo Borges et al (2012), substâncias fitoquímicas podem ser consideradas antimicrobianas quando a CIM estiver entre 100-1000 $\mu \mathrm{g} / \mathrm{ml}$. Em relação a atividades, de acordo com Morales et al. (2008), a inibição do crescimento bacteriano pode ser considerada: ativa, quando $\mathrm{CIM}<100 \mu \mathrm{g} / \mathrm{ml}$; moderada, quando CIM se encontra entre 100-500 $\mu \mathrm{g} / \mathrm{ml}$; fraca, quando CIM está entre 500-1000 $\mu \mathrm{g} / \mathrm{ml}$; sem atividade, quando $\mathrm{CIM}>1000 \mu \mathrm{g} / \mathrm{ml}$.

Baseado nesse critério, o extrato apresentou uma inibição moderada do crescimento bacteriano contra $P$. vulgaris e $V$. cholerae, uma fraca inibição contra $E$. coli, 
$P$. aeruginosa e $S$. aureus, e sem atividade antifúngica contra A. niger e $P$. notatum. Nesse caso, o extrato de B. orellana pode ser classificado como um agente antibacteriano.

A atividade antimicrobiana das sementes de $B$. orellana também foi evidenciada em relação às bactérias Streptococcus mutans e Streptococcus sanguinis (Medina-Flores et al., 2016). Sabe-se que em plantas, os polifenóis atuam no combate a infecções microbianas. Dessa forma, sua atuação se estende para vários tipos de microrganismos em estudos in vitro (Kumar; Pandey, 2013).

Os flavonoides podem se comportar como agentes antibacterianos através de três mecanismos diferentes: danos da membrana citoplasmática, inibição da síntese de ácidos nucleicos e pela inibição do metabolismo energético (Cushnie; Lamb, 2011). Sabe-se que os flavonoides são capazes de formar complexos com proteínas extracelulares e solúveis ou formar complexos com a parede bacteriana (Cowan, 1999). Dentre os compostos fenólicos encontrados no extrato de B. orellana, a alguns deles já foi atribuída atividade antibacteriana, como é o caso dos ácidos caféico, gálico e clorogênico, que demonstraram ser efetivos contra $S$. aureus (Luís et al, 2014).

\section{CONCLUSÃO}

Os dados obtidos neste estudo demonstram que o extrato acetônico de B. orellana mostrou-se como um importante ativo, apresentando atividade antibacteriana e a presença de fenóis e flavonoides, compostos de importante valor biológico. Como um produto natural, o urucum pode se tornar uma alternativa interessante no suporte a infecções bacterianas. Mais estudos são necessários para avaliar com mais precisão as propriedades antimicrobianas das sementes de B. orellana, assim como seus possíveis efeitos adversos e interações medicamentosas.

\section{REFERÊNCIAS}

BOLIGON, A.A.; PIANA, M.; KUBIÇA, T.F.; MARIO, D.N.; DALMOLIN, T.V.; BONEZ, P.C.; WEIBLEN, R.; LOVATO, L.; ALVES, S.H.; CAMPOS, M.M.A.; ATHAYDE, M.L. HPLC analysis and antimicrobial, antimycobacterial and antiviral activities of Tabernaemontana catharinensis A. DC. Journal of Applied Biomedicine, v.13, p.7-18, 2015.

BORGES, A.; SAAVEDRA, M.; SIMÕES, M. The activity of ferulic and gallic acids in biofilm prevention and control of pathogenic bacteria. Biofouling, v. 28, p. 37-41, 2012.

CHEYNIER, V. Phenolic compounds: from plants to foods. Phytochemistry Reviews, v. 11, p.153-177, 2012. 
COWAN, M.M. Plant Products as Antimicrobial Agents. Clinical Microbiology Reviews, v. 12, p. 564-582, 1999.

CUSHNIE, T. P. T.; LAMB, A. J. Recent advances in understanding the antibacterial properties of flavonoids. International Journal of Antimicrobial Agents, v. 38, p. 99107, 2011.

D’ARCHIVIO, M.; FILESI, C.; DI BENEDETTO, R.; GARGIULO, R.;

FACCHINI, P.J.; BOHLMANN, J.; COVELLO, P.S.; DE LUCA, V.; MAHADEVAN, R.; PAGE, J.E.; RO, D.K.; SENSEN, C.W.; STORMS, R.; MARTIN, V.J. Synthetic biosystems for the production of high-value plant metabolites. Trends Biotechnology, $v$. 30, p.127-31, 2012.

FLEISCHER, T.C.; AMEADE, E.P.K.; MENSAH, M.L.K.; SAWER, I.K. Antimicrobial activity of the leaves and seeds of Bixa orellana. Fitoterapia, v. 74, p.136-138, 2003.

GIOVANNINI, C.; MASELLA, R. Polyphenols, dietary sources and bioavailability. Annali dell'Istituto Superiore di Sanità, v. 43, p. 448-361, 2007.

GUESMI, A., HAMADI, N.B.; LADHARI, N.; SAKLI, F. Sonicator dyeing of modified acrylic fabrics with indicaxanthin natural dye. Industrial Crops and Products, v. 42, p.63-69, 2013.

HELENO, S.A.; MARTINS, A.; QUEIROZ, M.J.R.P.; FERREIRA, I.C.F.R. Bioactivity of phenolic acids: Metabolites versus parent compounds: A review. Food Chemistry, v. 173, p. 501-513, 2015.

KARMAKAR1, U.K.; SULTANA, S.; NISHI, S.; BISWAS, N.N.; HOSSAIN, L.; SHEIKH, S. Antioxidant, Analgesic, Antimicrobial, and Anthelmintic Activity of the Dried Seeds of Bixa orellana (L). International Journal of Pharmacy, v. 8, p.150-163, 2018.

KELLY, E.H.; ANTHONY, R.T.; DENNIS, J.B. Flavonoid antioxidants: chemistry, metabolism and structure-activity relationships. Journal of Nutritional Biochemistry, v. 13, p.572-584, 2002.

LEAL, F.; CLAVIJO, C.M. Annatto: a natural dye from the tropics. Chronica Horticulturae, v. 50, p. 34-36, 2010.

LUÍS, Â.; SILVA, F.; SOUSA, S.; DUARTE, A. P.; DOMINGUES, F. Antistaphylococcal and biofilm inhibitory activities of gallic, caffeic, and chlorogenic acids. Biofouling, v. 30, p. 69-79, 2014.

MEDINA-FLORES， D.; ULLOA-URIZAR， G.; CAMERE-COLAROSSI， R.; CABALLERO-GARCÍA, S.; MAYTA-TOVALINO, F.; VALLE-MENDOZA, J.D. Antibacterial activity of Bixa orellana L. (achiote) against Streptococcus mutans and Streptococcus sanguinis. Asian Pacific Journal of Tropical Biomedicine, v.6, p.400403, 2016. 
MISHRA, A.K.; MISHRA, A.; KEHRI, H.K.; SHARMA, B.; PANDEY, A.K. Inhibitory activity of Indian spice plant Cinnamomum zeylanicum extracts against Alternaria solani and Curvularia lunata, the pathogenic dematiaceous moulds. Annals of Clinical Microbiology and Antimicrobials, v. 8, p.1-7, 2009.

MORALES, G.; PAREDES, A.; SIERRA, P.; LOYOLA, L. Antimicrobial activity of three baccharis species used in the traditional medicine of Northern Chile. Molecules, $v$. 13, p. 790-794, 2008.

NCCLS. 2003. Methods for dilution antimicrobial susceptibility tests for bacteria that grow aerobically. Approved Standard, 6th ed. NCCLS document M7. Wayne, Pennsylvania, USA.

NEWMAN, D.J.; CRAGG, G.M. Natural Products as Sources of New Drugs over the Nearly Four Decades from 01/1981 to 09/2019. Journal of Natural Products, v. 83, p. 770-803, 2020.

PRIYA, R.; MADRID, R.R.; DOSS C.; G.P.; SINGH, P.; SIVA, R. Molecular modeling and dynamic simulation of Arabidopsis Thaliana carotenoid cleavage dioxygenase gene: A comparision with Bixa Orellana and Crocus Sativus. Journal of Cellular Biochemistry, v. 118, p. 2712-2721, 2017.

RIVERA-MADRID, R.; AGUILAR-ESPINOSA, M.; CÁRDENAS-CONEJO, Y.; GARZA-CALIGARIS, L.E. Carotenoid derivates in achiote (Bixa orellana) seeds: Synthesis and health promoting properties. Frontiers in Plant Science, v. 7, p. 1-7, 2016.

RODRIGUES, A. B.; ALMEIDA-APOLONIO, A. A. D.; ALFREDO, T. M.; DANTAS, F. G. D. S.; CAMPOS, J. F.; CARDOSO, C. A. L.; OLIVEIRA, K. M. P. D. Chemical Composition, Antimicrobial Activity, and Antioxidant Activity of Ocotea minarum (Nees \& Mart.) Mez. Oxidative medicine and cellular longevity, v. 2019, p.1-14, 2019.

SILVA, S.N.S.; AMARAL, C.L.F.; REBOUÇAS, T.N.H.; MORAIS, O.M. Adoption of conservation practices on farm and selection of varieties by producers of annatto in the city of Vitoria da Conquista - BA. Revista Brasileira de Agroecologia, v. 5, p.106-113, 2010.

WOJDYŁO, A.; OSZMIAN'SKI, J.; CZEMERYS, R. Antioxidant activity and phenolic compounds in 32 selected herbs. Food Chemistry, v.105, p. 940-949, 2007.

YONG YK, ZAKARIA ZA, KADIR AA, SOMCHIT MN, EE CHENG LIAN G, AHMAD Z. Chemical constituents and antihistamine activity of Bixa orellana leaf extract. BMC Complementary and Alternative Medicine, v. 13, p.1-7, 2013.

Recebido em: 03/02/2022

Aprovado em: 05/03/2022

Publicado em: 07/03/2022 